\title{
Does A Tone At The Top That Fosters Ethical Decisions Impact Financial Reporting Decisions: An Experimental Analysis
}

Jill M. D’Aquila (Email: jdaquila@iona.edu), Iona College, New Rochelle, NY David F. Bean (Email: dbean@iona.edu), Iona College

\begin{abstract}
The accounting profession believes the reliability of financial reporting is affected by an organization's internal control, the foundation of which relates to the tone at the top of an organization. Despite attempts by organizations to create ethical environments, financial accountants are sometimes confronted with ethical dilemmas that may affect financial reporting decisions.
\end{abstract}

An experiment that consisted of six different financial reporting scenarios was used to examine the influence of the tone at the top on financial reporting decisions. Subjects were assigned to three different organizational categories in terms of tone at the top - a tone that fosters ethical behavior, a tone that does not foster ethical behavior, and a neutral tone. The results support the position that tone at the top does relate to financial reporting decisions.

\section{Introduction}

A $\mathrm{n}$ organization's financial reports are utilized by many different users - stockholders, employees, suppliers, customers, etc.- who are influenced by the information contained in these financial reports when making decisions. The integrity of the financial reporting system is crucial to the efficiency and effectiveness of capital markets and the administration of tax laws. Each organization and user has a stake in the outcomes that are dependent upon the financial reports. An organization's significant investments in the extensive and sophisticated systems of internal controls, checks and balances, auditing requirements, etc. are essentially cost justified by the value placed on information that has integrity and reliability.

In response to incidences of improper financial reporting and other inappropriate behavior, many organizations have developed Codes of Conduct, training programs, and other initiatives to create environments that foster ethical decisions. The major purpose of these initiatives is to ensure that organizational members behave ethically when involved in activities both internal and external to the organization. Accountants are the primary organization personnel involved in the preparation of financial reports. The two largest organizations of accountants, American Institute of Certified Public Accountants and Institute of Management Accountants, have both issued comprehensive and detailed Codes of Ethical Behavior.

However, in spite of the time and resources invested in these initiatives fraudulent financial reporting still occurs. According to a survey conducted by the Association of Certified Fraud Examiners (ACFE 2002), fraudulent financial reporting is the most costly type of fraud, with a median loss of $\$ 4.25$ million per scheme. Furthermore, a

Readers with comments or questions are encouraged to contact the authors via email. 
survey of 5,000 organizations had revealed that fraudulent reporting is one of the most common types of fraud experienced (KPMG, 1998). A study of organizations that experienced fraudulent financial reporting or misappropriation of assets reveals that the average financial statement misstatement or misappropriation was $\$ 25$ million and the median was $\$ 4.1$ million (COSO, 1999). The following excerpts from a New York Times (Abelson, 2000) article about the Cendant Corporation contains some relevant anecdotal evidence about the causal variables of fraudulent reporting:

“. . . three former executives said today that for almost the entire history. . .its top executives directed a conspiracy to inflate profits. . .It was a culture that had been developing over many years. . .It was just ingrained in all of us, ingrained in us by our superiors, over a very long period of time. . . I just thought I was doing my job"

This incidence is one of numerous examples of fraudulent financial reporting and suggests that fraudulent reporting occurs when there is a culture in place that fosters it. Upper management appears to be able to influence organizational culture and the tone at the top of an organization may be a significant factor in the incidence of fraudulent reporting.

\section{Tone at the Top}

Studies commissioned by the accounting profession, as well as empirical research, suggests that upper management's creation and maintenance of an ethical (unethical) organizational culture (e.g. tone at the top) is a significant causal factor in the incidence of proper (fraudulent) financial reports. The National Commission on Fraudulent Financial Reporting (Treadway Commission, 1987), whose objective was to identify the causal factors of fraudulent financial reporting, believed the tone set by senior management (i.e., the corporate environment/culture) is the most important factor contributing to the integrity of the financial reporting process and has a pervasive impact on the entire process by which an organization's financial reports are prepared. As a result, the Commission made the following recommendations:

- Senior management identify and assess the factors that could lead to fraudulent financial reporting (p. 33);

- Senior management develop and enforce written codes of corporate conduct to foster strong ethical climates. The Committee suggested that a written code of corporate conduct strengthens the corporate ethical climate by signaling to all employees standards for conducting the company's business. Such codes could promote ethical decision making and help resolve ethical dilemma that arise (p. 35).

The Committee of sponsoring Organizations of the Treadway Commission (COSO), which continued the efforts of the Treadway Commission, notes:

"The effectiveness of internal controls cannot rise above the integrity and ethical values of the people who create, administer, and monitor them. Integrity and ethical values are essential elements of the control environment, affecting the design, administration and monitoring of other internal control components (1992, p. 19).”

This belief was reemphasized more recently by COSO (1999) based on their analysis of approximately 200 companies involved in alleged instances of fraudulent financial reporting from 1987 through 1997 . In 83\% of the cases, either the chief operating officer or the chief financial officer was reported as being associated with the financial statement fraud. Despite these findings, COSO (1999) noted that little empirical evidence existed about factors related to instances of fraud prior to their most recent study.

Research results suggest that employees often feel pressure to violate company policy and ethical values to achieve business objectives, and employees continue to witness unethical business practices at work (Ethics Resource Center, 1994; Soutar et al., 1994). The Ethics Resource Center (1994) found that lying on reports or falsifying records was reported to be one of the most common types of misconduct witnessed in organizations. 
Most researchers implicitly assume that employees are influenced by management (Baumhardt, 1961; Brenner and Molander, 1977;Ferrell and Gresham, 1985; Posner and Schmidt, 1984; Soutar et al., 1994; Treadway, 1987).

Empirical research has also consistently chronicled the influence of management in financial reporting. Basu (1992) investigated the evaluation of control environments by public accountants and found that management's attitude toward internal control was an important attribute. Rich, Smith, and Mihalek (1990) surveyed 3,000 members of the National Association of Accountants. Most respondents in their study were controllers and reported that they felt pressure to achieve targeted net income and return on investment. D'Aquila's (2001) study of 400 CPAs (primarily controllers and chief financial officers) supports the existence of pressures perceived by accountants. D'Aquila (1998) also found the perceived integrity of management to be positively correlated with fairly reported financial information. McKenna (1993) surveyed 491 chief financial officers of the Crain New York 600 firms and found that $35 \%$ of respondents perceived some to substantial concern that management would direct accountants to shift expenses between two accounting periods to smooth out net income. Posner and Schmidt (1984), who studied managers in general, reported that $73 \%$ of managers perceived this pressure as strong.

Baumhardt concluded, "If unethical practices are to be reduced, executives say that top management must lead the way. The men at the top must... reveal their ethical attitude, not only verbally, but also by forceful action" (1961, p. 7). In addition, Brief et al. (1996) indicated that establishing a corporate climate that encourages ethical decisions requires a sustained effort by senior management. However, Soutar et al. (1994) and the Ethics Resource Center (1994) concluded that upper management appears to be unaware of the increasing pressure and high incidence of ethical conflict reported by middle management. A partial explanation may be that in business decisions diverse motives often exist: financial, practical, administrative, technological, economic, competitive, corporate, organizational, social, personal, and ethical concerns, etc. (DiNorcia and Tigner, 2000). Decision making is also influenced by whether or not a problem is considered to be moral/non-moral and depersonalizing a problem can make it more likely to be classified as a non-moral problem (Dukerich et al. 2000). The example set by management is a frequently cited factor in unethical behavior (Baumhart, 1961; Brenner and Molander 1977; Ciulla 1998; Laczniak and Murphy 1991; Petrick and Quinn 1997; Stead et al. 1990; Wimbush and Shephard 1994; ZeyFerrell et al. 1982; and others). This implies that managers must become active advocates for their value systems and communicate consistent and appropriate messages (Dobni et al., 2000).

Research is encouraging with respect to the practical business questions that focus on 'what can ethical behavior do for me?' and 'what does it do for the bottom line?'. Organizational values give direction to the hundreds of decisions made at all levels of the organization every day (Schmidt and Posner, 1983). This enables the organization to become efficient and effective, and achieve associated cost savings. Research shows that consumers prefer to purchase from and invest in companies that are environmentally sensitive and display good behavior (Gilden, 1995). Organizations that adhere to ethical precepts have a significantly better chance of success than those engaged in dishonest and unethical behavior (Hosmir, 1994). COSO (1999) found that severe consequences awaited companies, as well as the employees involved in fraud. Consequences of financial statement fraud to organizations include bankruptcy, significant changes in ownership, and delisting by national exchanges, in addition to financial penalties. Over 50 percent of the organizations in their study were bankrupt or experienced a significant change in ownership after fraud was revealed.

Organizational values are important, as they create a unifying theme that provides meaning and direction for organizational members (James et al., 1990) and also function as a tool of social control that informally approves, constrains or prohibits behaviors (O’Reilly, 1989). Several researchers have suggested that the intraorganizational environment is a major determinant in the ethical decision making of employees (Bonczek, 1992; Dean, 1992; Fritzche, 1987; Reidenbach and Robin 1991). Blalock (1996) found that the tendency to commit fraud may be related to an ignorance of proper behavior, which suggests that organization members may be unaware of upper management's value system. Research consistently finds that the ethical philosophies and values of management significantly impact the behavior of organization members (D'Aquila, 1998; Stead et al. 1990; Soutar et al. 1994; Wimbush and Shephard, 1994). 
A CEO should clearly communicate the importance of ethical behavior in the organization and support this position through words and actions (Minkes et al., 1999). Organization members are influenced by upper management's communication of the values and ethics for which they stand. However, this has integrity only if the behavior of upper management is consistent with the communicated organizational values (Harshnan and Harshnan, 1999; Mc Donald, 2000). CEOs must communicate that an ethical organization is an essential and strategic component of the organization's vision; failure to do so will result in employees perceiving ethics programs for what they are - merely lip service.

\section{Research Questions}

One interpretation of the existing literature is that the creation of an ethical climate may deter fraudulent financial reporting, as well as other types of fraudulent behavior. The literature indicates that an appropriate tone at the top is a fundamental factor in fostering ethical behavior by organizational members. COSO (1992) described an appropriate tone at the top as one that includes explicitly moral guidance about right and wrong and demonstrates management's commitment to high ethical standards. Furthermore, management sets this tone through example (i.e., through words and actions). Despite these widespread assertions and beliefs, there is a void of empirical research to affirm or deny these positions. Thus:

\section{RQ1 Does the tone at the top of an organization relate to fraudulent financial reporting?}

The gender evidence with respect to ethical decision making is mixed (St. Pierre et al. 1990; Radtke, 2000). Harris (1990) indicated that gender has no significant effect on the degree of tolerance to fraud. Schmidt and Posner (1992) found that females rated the ethical behavior of senior management lower than did males, and found their own personal values to be less compatible with those of their organization. Larkin (2000) suggested that females are more able to identify ethical behavior. Additional empirical evidence is needed for this important issue. Thus:

RQ2 Does gender relate to fraudulent financial reporting?

\section{Method}

Subjects were randomly assigned to one of three types of organizational categories:

1. A tone at the top that fosters ethical decisions

2. A tone at the top that is neutral about ethical decisions.

3. A tone at the top that does not foster ethical decisions

Subjects then selected a course of action from a restricted menu of action choices they believe an employee would make in given accounting dilemma. Brief et al. (1996) indicate that such real life decision scenarios gauge behaviors that are not easily observed and have been used to study corporate fraud.

\section{Population and Sampling Frame}

Subjects consisted of 78 junior and senior business students enrolled in accounting courses at a private eastern U.S. college during the Spring 2000 and Spring 2002 semesters. Our decision to study students was based on the important role they play as future entrants to the business environment. We also believe that by exposing students to proper ethical behavior and environments, we are enhancing the probability of creating and enhancing ethical environments in the workplace. Only students with a class standing of junior and senior were included in our study since these students are believed to have obtained a certain level of understanding of accounting principles. The experimental instruments (Appendix A) were distributed to students enrolled in different accounting courses. Subjects were asked to respond anonymously by returning their responses in a blank, unmarked and sealed envelope to assure confidentiality. A demographic profile of the responses is reported in Table 1. 
Table 1: Demographic Characteristics of Respondents

\begin{tabular}{lcr}
\hline Characteristics & $\boldsymbol{N}$ & $\boldsymbol{\%}$ \\
\hline Gender & & 53.8 \\
Male & 42 & 46.2 \\
Female & 36 & \\
& & 46.2 \\
Class Standing & & 53.8 \\
$\quad$ Junior & 36 & \\
Senior & 42 & \\
\hline
\end{tabular}

\section{Experimental Instrument}

One of the three versions of the experimental instrument was distributed to each subject. The instrument described three different versions of a tone at the top of an organization where a fictitious employee worked. The tone at the top was described as follows for the organization (1) fostering ethical behavior, (2) neutral with respect to ethical behavior, and (3) not fostering ethical behavior:

1. The organization is profit oriented and sets high objectives for its members. Upper management expects that its employees will adhere to high ethical standards to meet these agreed upon objectives. Since the company believes that the tone of the organization starts with the top, managers try to set good examples through their own behavior. Recently the company incurred significant costs to rectify a potential problem relating to a defective product, even though they did not believe they were legally required to do so. Each year, the company requires all employees to attend training workshops, which offer employees an opportunity to discuss ethical dilemmas and possible courses of action.

2. The organization is profit oriented and sets high objectives for its members. Upper management expects that its employees will meet these agreed upon objectives. Each year, the company requires all employees to attend training workshops on various work-related issues.

3. The organization is profit oriented and sets high objectives for its members. Upper management expects that its employees will use any measure to meet these agreed upon objectives. On occasion, employees have witnessed management bending some rules "to accomplish a business goal". There have also been times when employees believed management also expected them to "bend some rules" to accomplish business goals. Recently, the company developed a product with a potential defect and did not rectify the problem because of cost considerations. If employees ever encountered unethical behavior, they are not exactly sure where they would turn for help.

The remainder of the instrument was identical for all three versions (see Appendix A for a complete version). The experimental instrument described six accounting dilemmas, constructed from actual Security and Exchange Commission cases that address fraudulent financial reporting issues, in addition to a business dilemma to disguise the intent of the research. The questions vary by type of financial reporting. Each scenario provided the employee with a motive (e.g. bonus) to misrepresent the organization's financial statements. Subjects were requested to circle one of five answers that best describe what an employee in that organization would do in the given situation. The forced choices ranged from (1) misrepresenting the organization's financial statements by a significant degree to (5) not misrepresenting the organization's financial statements. For each dilemma choice (5) was the ethical response, and choices (1) through (4) were financial misrepresentations (unethical choices) with decreasing degrees of misrepresentation. ${ }^{1}$ Mean scores were computed and a higher (lower) score reflects a more

\footnotetext{
${ }^{1}$ The answer choices on the questionnaire are reversed for one of the ethical dilemmas (a lower score reflects a more ethical decision). During the analysis, the scores were transformed to correspond with the scoring used for the other 5 dilemmas.
} 
ethical (unethical) decision. The accounting dilemmas were based on a questionnaire developed by Brief, et al. (1996).

\section{Results:}

As reported in Table 2, analysis of variance indicates a significant difference in financial reporting decisions made by subjects placed in organizations with different tones at the top for one of the six dilemmas (Case 2). Although the remaining five dilemmas disclosed no significant difference, there were directional differences between the different tone at the top conditions and all six dilemmas, as reported in Table 3. This Table reveals that in all six cases, subjects assigned to a negative tone at the top had the lowest mean scores (less ethical choice). Subjects assigned to either an ethical or neutral tone at the top had the highest mean scores (more ethical choice). A range of mean scores for the cases of 2.81 to 4.30 indicates that, on average, subjects believe that employees would misrepresent financial information by less than a moderate amount (i.e. a score of 1 indicates a large misrepresentation whereas a score of 5 indicates no misrepresentation). T-tests disclosed no significant differences when subjects were analyzed by gender.

Table 2: Analysis of Variance - Case 2

\begin{tabular}{|l|c|c|c|c|c|}
\hline & Sum of Squares & Df & Mean Square & F & Sig \\
\hline Between Groups & 8.287 & 2 & 4.143 & 2.979 & .057 \\
\hline Within Groups & $102 . .934$ & 74 & 1.391 & & \\
\hline Total & 111.221 & 76 & & & \\
\hline
\end{tabular}

Table 3: Mean Scores

\begin{tabular}{|c|c|c|c|c|}
\hline Case & $\begin{array}{c}\text { Tone Fosters } \\
\text { Ethical Decisions }\end{array}$ & Neutral Tone & $\begin{array}{c}\text { Tone Does Not } \\
\text { Foster Ethical } \\
\text { Decisions }\end{array}$ & All Respondents \\
\hline $\mathbf{1}$ & $(\mathrm{N}=27)$ & $(\mathrm{N}=23)$ & $(\mathrm{N}=28)$ & $(\mathrm{N}=78)$ \\
\hline $\mathbf{2}$ & $3.41^{*}$ & 3.35 & $3.11^{* *}$ & 3.28 \\
\hline $\mathbf{3}$ & $3.96^{*}$ & 3.83 & $3.22^{* *}$ & 3.66 \\
\hline $\mathbf{4}$ & $2.89^{*}$ & 2.87 & $2.68^{* *}$ & 2.81 \\
\hline $\mathbf{5}$ & 4.07 & $4.17^{*}$ & $3.71^{* *}$ & 3.97 \\
\hline $\mathbf{6}$ & 4.04 & $4.30^{*}$ & $3.93^{* *}$ & 4.08 \\
\hline
\end{tabular}

An additional analysis was performed in order to address potential subject/response distribution characteristics. The non-parametric test, Dunn's Multiple Comparison Test (Hollander and Wolfe 1973), disclosed a significant difference, at the .10 level, for Case 2. This significant difference was between the responses of those placed in the positive tone at the top condition and those placed in a negative tone at the top condition.

\section{Discussion}

Our experimental manipulation of the tone at the top was limited because of the nature of the study. Therefore we did not expect to acquire results that would definitively settle or narrow empirical research efforts about the tone at the top. However, we did meet our expectation to provide guidance for future research efforts in this important area. The results suggest that when personnel are placed in a tone at the top that does not foster ethical decisions, they are more likely to choose unethical responses. 
Our choice of students, as subjects, was purposeful. Many believe that it is difficult for students to relate to the importance of organizational culture(s) and its impact on organizational decisions and outcomes. However, our interpretation of the experimental results is that students recognize and respond to cultural organizational norms. We believe that the creation of ethical environments in organizations is enhanced by the recruitment of personnel who have experienced an ethical environment and have an expectation of working in an ethical environment. Most institutions of higher learning have "Codes of Ethics" for both students and faculty. However, students are similar to "real world" organization members. The mere existence of a "Code of Ethics" is inadequate. Students must experience the embodiment of such codes in the classroom and in interactions with other representatives of the institution. Faculty members are the primary exemplars for students. As such, it is crucial that faculty embrace and reflect the code in their interactions with students. Faculty, as well as managers in an organization, must "practice what they preach". If an educational institution cannot create a living model of an ethical environment, then what hope can possibly exist for its graduates?

As with other initial empirical forays, there are a number of self-evident limitations to this research study that are typical to behavioral research (e.g. forced choice, laboratory versus real world decision making, etc.). Additional empirical research is needed and encouraged. Such research should consider different scenarios and diverse subjects. Furthermore, samples from both student and working subjects would assist in identifying where and when the focus on "ethical environments" is most appropriate and effective.

\section{References}

1. Abelson, R. (2000). 'The Road to Reviving a Reputation', New York Times, June 15, pp C1 and C8.

2. Association of Certified Fraud Examiners (ACFE). 2002 Report to the Nation: Occupational Fraud and Abuse, Austin, TX, 2002.

3. Basu, P. (1992). 'The Influence of Client Control Environment Attributes on Evaluation of Internal Control: An Empirical Investigation of Auditor Judgment', Unpublished Doctoral Dissertation, University of Nebraska.

4. $\quad$ Baumhardt, R.C. (1961). 'How Ethical Are Businessmen?', Harvard Business Review, 39 (4), 7-176.

5. Blalock, D.: 1996, 'Study Shows Many Execs Are Quick to Write Off Ethics', Wall Street Journal, March 26, C1, C15.

6. Bonczek, S. J. (1992). 'Ethical Decision Making: Challenge of the 1990's-A Practical Approach for Local Governments', Public Personnel Management, 21, 75-88.

7. Brenner, S. N. and E. A. Molander. (1977). 'Is the Ethics of Business Changing?' Harvard Business Review, 5 (1), 57-71.

8. Brief, A.P., J. M. Dukerich, P.R. Brown, and J. F. Brett (1996). 'What's Wrong With The Treadway Commission Report? Experimental Analysis of The Effects of Personal Values and Codes of Conduct on Fraudulent Financial Reporting', Journal of Business Ethics, 15, 183-198.

9. $\quad$ Ciulla, J.B. (ed) (1998). 'Ethics: The Heart of Leadership', Preager, Westport

10. Committee of Sponsoring Organizations of the Treadway Commission (COSO). (1992). Internal Control-Integrated Framework.

11. Committee of Sponsoring Organizations of the Treadway Commission (COSO). (1999). Fraudulent Financial Reporting: 1987-1997 - An Analysis of U.S. Public Companies.

12. D'Aquila, J. (1998). 'Is The Control Environment Related to Financial Reporting Decisions?', Managerial Auditing Journal, 13 (8), 472-478.

13. D'Aquila, J. (2001). Financial Accountants' Perceptions of Management's Ethical Standards. Journal of Business Ethics 31, 233-244.

14. DiNorcia V. and J. Tigner. (2000). 'Mixed Motives and Ethical Decisions in Business', Journal of Business Ethics, 25, 1-13.

15. Dean, P.J. (1992). 'Making Codes of Ethics "Real”', Journal of Business Ethics, 11, 285-290.

16. Dobni, D., J.R. Brent Ritchie and W. Zerbe (2000). 'Organizational Values: The Inside View of Service Productivity', Journal of Business Research, 47, 91-107.

17. Dukerich, J.M., M.J. Waller, E. George and G. Huber (2000). Moral Intensity and Managerial Problem Solving', Journal of Business Ethics, (24), 29-38 
18. Ethics Resource Center, Inc. (1994). New Nationwide Employee Survey Finds Comprehensive Ethics Programs Effective in Changing Corporate Attitudes, Behavior.

19. Ferrell, O.C. and L. G. Gresham (1985). 'A Contingency Framework for Understanding Ethical Decision Making in Marketing', Journal of Marketing, 55-64.

20. Fritzsche, D.J. (1987). 'Marketing/Business Ethics: A Review of the Empirical Research', Business and Professional Ethics Journal, 6, 65-79.

21. Gilden, R.L. (1995). 'Consumer Survey Confirms Corporate Social Responsibility Affects Buying Decisions', Public Relations Quarterly, 39, 20-21.

22. Harris, J.R. (1990). Ethical Values of Individuals at Different Levels in the Organizational Hierarchy of a Single Firm. Journal of Business Ethics 9: 741-750.

23. Harshnan, E. F. and C. L. Harshan (1999). 'Communicating With Employees: Building on an Ethical Foundation', Journal of Business Ethics, 19, 3-19.

24. Hollander, M. and D. A. Wolfe (1973). 'Nonparametric Statistical Methods', John Wiley and Sons, 125127.

25. Hosmir, L. (1994). 'Strategic Planning as if Ethics Mattered', Strategic Management Journal, 15, 17-34.

26. James, L.R., L. A. James and D. K. Aske (1990). 'The Meaning of Organizations: The Role of Cognition And Values in Organizational Climate and Culture', B. Schneider editor, Jossey-Bass, San Francisco, 4084.

27. $\quad$ KPMG (1998). 1998 Fraud Survey. Montvale, NJ.

28. Laczniak, G.R. and P.E. Murphy (1991). 'Fostering Ethical Marketing Decisions', Journal of Business Ethics, 10, 259-271

29. Larkin, J.M. (2000). 'The Ability of Internal Auditors to Identify Ethical Dilemmas', Journal of Business Ethics, 23, 401-409

30. McDonald, G. (2000). 'Business Ethics Practical Proposals for Organizations', Journal of Business Ethics, $25,169-184$

31. McKenna, J.N. (1993). 'Ethical Dilemmas in Financial Reporting Situations And the Preferred Mode of Resolution of Ethical Conflicts as Taken by Certified and Noncertified Management Accountants in Organizations With Perceived Different Work Climates' Unpublished doctoral dissertation, New York University.

32. Minkes, A. L., M. W. Small and S. R. Chatterjee (1999). 'Leadership and Business Ethics: Does it Matter? Implications for Management', Journal of Business Ethics, 20, 327-335.

33. O'Reilly, C. (1989). 'Corporations, Culture and Commitment: Motivation and Social Control in Organizations', California Management Review, (summer), 9-25.

34. Petrick, J. A. and J. F. Quinn (1997). 'Management Ethics: Integrity at Work', Sage Publications, Thousand Oaks.

35. Posner, B.Z. and W. H. Schmidt (1984). 'Values and the American Manager. An Update', California Management Review, 20 (3), 202-216

36. Radtke, R.R. (2000). 'The Effects of Gender and Setting on Accountants' Ethically Sensitive Decisions', Journal of Business Ethics, 24, 299-312.

37. Reidenbach, R.E. and D.P. Robin (1991). 'A Conceptual Model of Corporate Moral Development', Journal of Business Ethics, 10, 273-284.

38. Rich, A.J., C.S. Smith and P.H. Mihalek (1990). 'Are Corporate Codes of Conduct Effective?', Management Accounting, 34-5.

39. Schmidt, W.H. and B.Z. Posner (1983). 'Managerial Values in Perspective'. American Management Association, New York

40. Schmidt, W.H. and B.Z. Posner. (1992). The Values of American Managers Then and Now. Management Review 81: 37-40.

41. Soutar, G., M.M. McNeil, and C. Molster (1994). 'The Impact of the Work Environment on Ethical Decision Making: Some Australian Evidence', Journal of Business Ethics, 13, 327-339.

42. Stead, W.E., D.L. Worrell and J.G. Stead (1990). 'An Integrative Model for Understanding and Managing Ethical Behavior in Business Organizations', Journal of Business Ethics, 13, 63-69.

43. St. Pierre, K., E. Nelson and A. Gabbin (1990). 'A Study of the Ethical Development of Accounting Majors in Relation to Other Business and Nonbusiness Disciplines', The Accounting Educators Journal, 3, 23-35. 
44. Treadway, J.C. Jr. (1987), Report of the National Commission on Fraudulent Financial Reporting, National Commission on Fraudulent Financial Reporting (Treadway Commission), Washington, DC, October

45. Wimbush, J.C. and J.M. Shepard (1994)..’Toward an Understanding of Ethical Climate: It's Relationship to Ethical Behavior and Supervisory Influence', Journal of Business Ethics, 13, 637-647.

46. Zey-Ferrell, M and O. C. Ferrell (1982). 'Role-set Configuration and Opportunity as Predictors of Unethcial Behavior in Organizations', Human Relations, 35, 587-604

\section{Appendix}

\section{DECISION MAKING QUESTIONNAIRE}

This section consists of 7 different questions, each of which requires you to make a decision about what action you believe the employee would take. Most of the questions are based on actual incidents and are designed to capture how individuals make managerial decisions. Your answers are completely confidential. Do not put your name on the answer sheet.

Read each question in the enclosed packet carefully. Then, select one of the decision alternatives that will be provided to you below. Move through the questions as quickly as possible. But, be sure each decision you make reflects what you believe the employee would actually decide given the situation described in the question. That is, each of your decisions should not be based on how you hope the employee would behave, but must indicate how you think the employee really would act.

Remember: (a) read each question very carefully, (b) select the most realistic decision alternative in responding to each question; and (c) move through the questions as quickly as possible.

\section{DESCRIPTION OF THE ORGANIZATION WHERE EACH EMPLOYEE WORKS}

The organization is profit oriented and sets high objectives for its members. Upper management expects that its employees will adhere to high ethical standards to meet these agreed upon objectives. Since the company believes that the tone of the organization starts with the top, managers try to set good examples through their own behavior. Recently, the company incurred significant costs to rectify a potential problem relating to a defective product, even though they did not believe they were legally obligated to do so. Each year, the company requires all employees to attend training workshops, which offer employees an opportunity to discuss ethical dilemmas and possible courses of action. EMPLOYEE WOULD TAKE.

********************************************************************************************************

\section{Case 1: Creative Creatures, Inc. - SHOULD SID ...}

1. Do nothing and hope the test market specialists are wrong.

2. $\quad$ Go to the CEO and tell him at least a $4 \%$ return reserve is needed.

3. Go to the CEO and tell him at least a $6 \%$ return reserve is needed.

4. $\quad$ Go to the $\mathrm{CEO}$ and tell him at least a $8 \%$ return reserve is needed.

5. Go to the CEO and tell him a $10 \%$ return reserve is needed.

\section{Case 2: First National Bank Corporation - WHAT SHOULD HE DO?}

1. Strictly adhere to the cost containment guidelines and not let anyone go to the workshops.

2. Only let the managers send the two most senior people on their staffs. 
3. Only let the managers send the two top performers on their staff.

4. Ask the managers to choose one woman and one minority member.

5. Forego the guidelines and do not restrict attendance at the workshop.

\section{Case 3: Polansky Manufacturing - WHAT SHOULD WALLY DO?}

1. Include the entire cost of the plane in the contract.

2. Include $75 \%$ of the cost of the plane in the contract.

3. Include $50 \%$ of the cost of the plane in the contract.

4. Include $25 \%$ of the cost of the plane in the contract.

5. Not include any of the costs of the plane in the contract.

Case 4: Jose's, Inc. - HOW MUCH OF THE VALUE OF JOSE'S INACTIVE UNITS SHOULD TODD WRITE OFF THIS YEAR?

1. Nothing, he should not take a write-off on the inactive units this year.

2. Less than $\$ 1$ million

3. $\$ 1$ to 2 million

4. $\quad \$ 2$ to 3 million

5. The entire $\$ 3.1$ million should be written off.

Case 5: Nutron, Inc. - HOW MANY DAYS DO YOU THINK NEAL SHOULD WAIT BEFORE HAVING THE ORDER SHIPPED?

1. None, he should ship the order immediately

2. 2 - 4 days

3. $5-7$ days

4. 8 - 10 days

5. He should not ship the order until after the deal is closed and a contract is signed.

Case 6: Daytona Auto Parts Corporation - PAT SHOULD ...

1. Not sign the inventory report. Rather she should submit a report regarding her concerns to her boss, Mr. Brown.

2. Sign off in the inventory report but also speak to Mr. Norman, the Regional Manager, about her concerns.

3. Sign off in the inventory report and then talk with her boss regarding her concerns.

4. Sign off in the inventory report and document her concerns in an internal memorandum for the file.

5. Sign the inventory report and do and say nothing else.

Case 7: DMC Corp. - HOW SHOULD ED HANDLE THE SITUATION?

1. Disregard the tip as farfetched.

2. Send a formal letter to the Controller thanking him for putting in the tight internal controls and reminding him of the importance of these procedures.

3. Ask the RFO to send him a formal confirmation that the Region's internal control procedures are sound.

4. Wait a few weeks after returning to Corporate Headquarters and send the President a note about the anonymous letter, indicating it's just too farfetched to believe.

5. Immediately inform the President of the letter and proceed to ask specific questions to investigate all of the allegations in the letter. 


\section{DECISION MAKING QUESTIONS}

\section{Case 1: Creative Creatures, Inc.}

Sid just returned from a meeting with the Controller. The meeting not only ruined his day, but possibly his newfound status as a "boy wonder" at Creative Creatures, Inc. As Vice President of Product Development, Sid manages the group that has been working on a new line of Crazy Creatures toys which is due out in time for the Christmas season. However, early test market results showed that one out of ten "Crazies" could be returned because of malfunction. And, there is just no way to correct the problem before the toys are to be shipped for the Christmas season. So, Sid has to get the Controller to increase the return reserves from $2 \%$ to $10 \%$ for this particular line, or the company will be overstating profits on its sales. That is, conventional accounting practices dictate that return reserves represent a cost of doing business and must be subtracted from revenues in estimating profits in a given accounting period.

Creative Creatures believes in quality first. Because they pride themselves on such high quality, they've had very few returns in the past and, correspondingly, allocate only a small amount to cover potential returns. When Sid approached the Controller with his problem, the Controller refused to deviate from the minimal return reserve policy. Sid knows that if returns are as high as he suspects they will be, sales will be seriously overstated. He knows that he should discuss the problem with the CEO. However, the CEO has invited Sid and his wife to join them for a trade show in London. (Sid's never been to Europe before and fears that if he reports the problem to the CEO he can kiss the trip goodby. Indeed, he thinks he'll be lucky if that's all the CEO does to him.)

He also believes that test market specialists are sometimes overly cautious in their projections. So, a one out of ten return rate simply may not materialize. Sid doesn't know what to do.

\section{Case 2: First National Bank Corporation}

John Kramer is facing a really sticky dilemma. John is the Vice President of the Merchant Credit Card Department at a large Midwestern bank, First National Bank Corporation. His department recently added several large accounts which helped to far exceed their performance objectives for the first three quarters. Moreover, John expects the fourth quarter to be equally successful. First National Bank Corporation as a whole, however, is not having such a good year. In fact, fourth quarter projections for the Corporation indicate current profits to be below last year. As a result, the Corporation has frozen non-executive salaries, put a moratorium on hiring, and is scrutinizing all employee expenses for travel and entertainment.

John was made aware of his current dilemma by his Administrative Assistant who monitors the Department's budget. According to Sam, the Assistant, not only has the Department failed to adhere to the Corporation's new and rather conservative travel and entertainment policies for the third quarter, but projections for the fourth quarter indicate travel and entertainment expenses will be $30 \%$ over budget. A major reason for this rather large fourth quarter expenditure is that several of John's managers authorized more than a dozen of the Department's staff to attend an American Banking Society workshop in Honolulu. Usually such expenditures wouldn't bother John, especially when his Department is having such a good year. But, the Corporation is in trouble.

John knows that if he wants to be perceived by his boss as a good team player, he'll have to cancel most of his folk's trips to Hawaii. He also knows, however, how hard the staff in his Department has worked this year. The recently added new business, coupled with the Corporation's hiring freeze, has created many 60 hour work weeks for the staff members. Moreover, they probably would make some valuable contacts at the workshop in Hawaii. John knows, nevertheless, that his reputation as a good administrator and team player would be jeopardized if he lets expenses get too far out of line and that could hurt his year-end bonus. While his Department's strong performance should justify a good bonus, not towing the line on cost-containment would raise questions with the President. 
One possible compromise is to restrict the number of staff members going to the workshop. The dilemma, then, is determining the criteria by which some staff members will be selected to go to Hawaii. He could ask his managers to send only the two most senior people on their staffs to the workshop. Unfortunately, this would exclude any women or minorities from going. Alternatively, he could let his managers send only the top two performers on their staffs; but again, this would exclude women and minorities and they could probably benefit the most from the experience.

\section{Case 3: Polansky Manufacturing}

Wally Polansky, CEO of Polansky Manufacturing, really wants a company plane. He finds it an irritation and often time consuming to rely on public air transportation. Some of his plants across the country can't be reached by commercial airlines, so that means driving several hours when he wants to inspect some plants. Ever since Wally started out with just one plant, he's been the kind of owner who wants his presence to be known, thus, he frequently visits his plants.

Polansky Manufacturing is negotiating a new contract with the Department of Defense (DOD) to produce machine parts. Wally knows that, in a strict sense, the cost of the plane probably shouldn't go into the contract's overhead. Nevertheless, he still figures he may be able to justify charging the DOD something. The contract calls for parts that will be manufactured at more than one of his plants. A plane would allow him to visit all of these plants, thus ensuring that the production schedule and contract specifications are met. Wally wonders how much of the cost of the plane he can include in the overhead costs of the contract.

\section{Case 4: Jose's, Inc.}

Todd knows that very soon now he or one of JOSE'S two Executive Vice Presidents will be named President by the Board's Personnel Committee. He also knows the race is darned close. He and the two EVPs have been with the restaurant chain since it consisted of only five or six units. JOSE'S currently is comprised of more than 135 units, plus a rapidly growing frozen food business.

Todd has a great deal of responsibility. As the firm's Chief Financial Officer, he is responsible for finding the capital to maintain JOSE'S planned expansion. In addition, the firm's Controller, Legal Counsel, and Vice Presidents of Human Resources, Information Systems, and Real Estate report to him. It's a rare week when Todd works less than 60 hours.

Todd has just learned of a "potential bookkeeping mistake" from someone on the Controller's staff that he is afraid may cost him the President's job. As the firm expanded over the years, a few units, due to shifting market conditions, had to be closed down. The value at which these inactive units are carried on the firm's books is based upon the market price of the units at the time each unit was closed (\$5.1 million for the land, building, and equipment). However, the value of all units has dropped drastically since they have been closed because of (a) decreasing land prices in the neighborhoods the units are located, (b) vandalism, including two units completely destroyed by arson, and (c) inadequate maintenance of equipment. The true value of the inactive units probably is less than $\$ 2.0$ million.

It is now the end of December. Since JOSE'S year end statements are being prepared, Todd needs to decide if he should authorize a write-off of the firm's assets at this time to reflect the drop in the value of the inactive units. Such a write-off would cut deeply into JOSE'S profits for the year. Therefore, the firm would be less attractive to those from whom Todd solicits the capital funds needed for expansion. In addition, Todd also knows that a sizable write-off right now would kill his chances for promotion. The announcement of who will assume the President's position is scheduled for the first of the year. 


\section{Case 5: Nutron, Inc.}

Neal is anxious, very anxious. As Chief Operating Officer of Nutron, Inc., which manufactures a line of quality AM/FM receivers, much of his income is in the form of a bonus tied to annual earnings. Neal and his brother have a large real estate loan coming due and he's counting on a particularly large bonus this year. But, only 11 days remain in the fourth quarter and revenues are below those needed to boost earnings up to the level Neal had expected. If something positive doesn't happen real soon, he and his family will be facing a crisis.

Neal's only hope is Sound Systems, a large Dallas based retailer. Sound Systems is very close to placing an order for receivers that will generate more than enough revenues to keep Neal out of trouble. Neal is almost certain they will close the deal in a week or two. He has decided to wait a few more days; and, if Sound Systems is still holding out, he may ship them the goods anyhow. This way, revenues will be recorded by year's end and Sound Systems will be delighted to get their receivers earlier than expected.

\section{Case 6: Daytona Auto Parts Corporation}

Until today Patricia Lewis has been unbelievably enthusiastic about her new job as Senior Internal Auditor for Daytona Auto Parts Corporation. She is proud to be one of the firm's few women supervisors and the very first female auditor to be hired into the Corporate Auditing Group. One of her first assignments has been to review the year end inventory procedures followed by the outlets located in the Southwest Region. This is an important, but potentially tricky assignment. Not only does this Region have the most outlet stores; but Mr. Norman, the Region's Manager, is an old golf buddy of her boss, Mr. Brown, Vice President of Internal Auditing. Mr. Norman, whose nickname is "Stormin' Norman," has a reputation for being quite an arrogant so-and-so. Patricia's task was to review the inventory procedures and certify that they were sound. She knew that if anything went wrong, Mr. Norman would be on the phone with her boss immediately and would make her life very miserable.

After spending almost a week in the Southwest Region reviewing the inventory procedures that were used, Patricia Lewis was scared. The procedures that the Regional Office follow include counting inventory at different locations on different days of the week. Believing that this was not appropriate, Patricia recommended to Mr. Norman that the inventory procedures should be modified. Mr. Norman justified the present practice to Patricia by arguing that the approach was required because of the need to leave some stores open to serve customers. That is, he didn't want to close all of the stores at the same time just to take inventory. Also, he said it was impossible to get enough qualified help to count inventory in all the stores on the same day.

Now Patricia wishes she had taken a stronger stand. As soon as the inventory count began her suspicions grew. In the stores she had visited during the inventory, Patricia saw a substantial number of parts just inside the store rooms. The crates did not have any shipping information details attached to them. It was unclear as to the date these parts arrived or how long they had been in the stores. It was an unusual practice not to have the details on the crates. Pat suspects that because this information is missing, inventory was moved from store to store to inflate the amount at each outlet.

As the first woman in her job, Patricia desperately wants to succeed. But, she's afraid if she rocks the boat she may get fired. Since her boss and Mr. Norman are such good pals, she's almost certain that if she brings the inventory problem up with Mr. Brown, he will just go along with Mr. Norman and approve the inventory procedures. Should she rock the boat and say something or just sign-off on the procedures and inventory totals?

$$
* * *
$$

\section{Case 7: DMC Corp.}

Ed Dantene should be happy. His temporary assignment as Regional Director of the DMC Midwest Office will soon be over. Ed has worked eight years for DMC Corp., a Philadelphia based firm primarily engaged in employee benefits services and investment management. He considered it an honor and a great experience for 
someone of his age to be asked by the President to temporarily replace Mr. Zucco, the Midwest Regional Director, while he recuperated from back surgery. The assignment has been challenging, but, the commuting back and forth to Philadelphia from Indiana on the weekends has been tough on Ed, his wife, and their three kids. So, Ed is especially excited to return home and looking forward to a new position that awaits him in the Corporate Offices.

The Vice President of Operations, the Regional Financial Officer, the Controller, and the Personnel Director report to Ed in his position as Acting Regional Director. It's a good Regional Office that has consistently reported an annual return on its investments in excess of $10 \%$ and has never had one unprofitable month.

Although Ed should be happy, he presently is facing a dilemma. Last week, Ed received an anonymous letter informing him that some of the Region's investment and accounting practices may be suspect. The letter implied that the Investment Department did not record that it lost large amounts of money on some of its investments. Further, the letter stated that the bookkeeper in the Investment Department who is supposed to record investment transactions and their status is having a problem with alcohol. Ed doesn't know what to do.

He was afraid of something like this. When he first came into the Region he raised questions to the Regional Financial Officer (RFO) and Controller about the internal control procedures. The RFO had looked into the issue and gave Ed informal assurances over lunch that the procedures were "darn" sound. On the other hand, the Controller sent Ed a list of changes he wanted to make in the internal controls. Ed didn't know if these were in place not or not; he just assumed that the Controller had put them in place.

Now everything seemed to be falling apart. To investigate the allegations would take days. There would be serious ramifications for the Company if the anonymous tip was true. But, Ed also knew that if the President knew of this he would ask him to stay in the Region until everything was resolved. Ed was tired of the Midwest and wanted to be with his family and friends in Philadelphia.

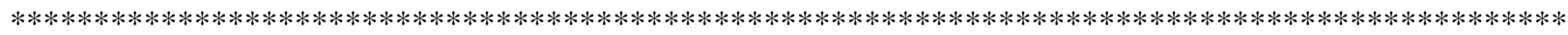

******************************************************************************************************* 